\title{
Phytochemical Study of Underutilized Leaves of Cola acuminata and C. nitida
}

\author{
Otoide Jonathan Eromosele*, Olanipekun Mary Kehinde
}

Faculty of Science, Department of Plant Science and Biotechnology, Ekiti State University, Ado-Ekiti, Nigeria jonathan.otoide@eksu.edu.ng

Abstract: Human dependence on natural crude drugs as remedies increases day after day and there are still very many plants/ plant parts whose medicinal values are yet to be established. Research is still ongoing to bridge the gap by extracting the active ingredients in plants for preparation of useful drugs by pharmaceutical industries. Interestingly, the medicinal values of the nuts, barks and roots of the two species of Cola in the present study have been reported by some researchers. However, there is no information regarding the phytochemistry of the leaves of this species. Therefore, the present study is the first to provide information on the phytochemistry of leaves of Cola acuminata and C. nitida. The Phytochemistry of the leaves was carried out using standard procedures. The results of the study revealed the presence of useful phytochemicals. Averages of $70.03 \pm 23.34(\mathrm{mgQE} / \mathrm{g}), 22.96 \pm 7.65(\mathrm{mgGAE} / \mathrm{g}), 13.44 \pm 4.48(\mathrm{mgTAE} / \mathrm{g}), 1.01 \pm 0.34(\mathrm{mg} / \mathrm{g})$, and $0.16 \pm$ $0.05(\mathrm{mg} / \mathrm{g})$ were the quantities of flavonoids, phenols, tannins, alkanoids and saponins in the leaf of C.nitida respectively. Whereas, the leaf of $C$. acuminata contained $26.71 \pm 12.24$ (mgQE/g), $23.52 \pm 7.84(\mathrm{mgGAE} / \mathrm{g})$, $15.32 \pm 5.11(\mathrm{mgTAE} / \mathrm{g}), 1.23 \pm 0.41(\mathrm{mg} / \mathrm{g})$ and $0.22 \pm 0.07(\mathrm{mg} / \mathrm{g})$ of flavonoids, phenols, tannins, alkanoids and saponins respectively. The relevance of the phytochemicals was discussed with a view to increasing the utility of the leaves by humans.

Keywords: underutilized, leaves, phytochemicals

\section{INTRODUCTION}

Cola acuminata is a tree that grows up to $20 \mathrm{~m}$ tall, usually less in cultivation. The bole commonly branches close to the ground. It is claimed in Nigeria that the root has aphrodisiac property. It is used in the Borno area as a stimulant. The leaves, not specifically reported to contain any active principle, are also said to be taken in Borno as a stimulant (Burkill, 2000). The fruit is composed of up to 5 carpels, to $20 \mathrm{~cm}$ long by $6 \mathrm{~cm}$ broad, with as many as 14 seed covered with a white skin. The number of cotyledons is usually $3-5$. The seeds are generally red or pink, but occasionally white. The latter are preferred, commanding a higher price and have special significance for ritual. A tree may have nuts of different colours, but self-pollinated white bearing trees produce only white nuts.

The bark shows a strong presence of alkaloid. In Congo and Ivory Coast, Preparations are recommended for abdominal troubles generally, especially of women, in palm-wine or pulped in water taken by draught or in enema as an ecbolic. Bark has use in bronchial affection as an expectorant and with a little salt and seed of Xylopia aethiopica (Annonaceae) to relieve cough and colic. It is said to cause release of bile. A decoction has healing property in cleansing sores and maturating furuncles and buboes. The bark mixed with bark of Khaya (Meliaceae) is said to produce a brown dye (Irvine, 1961 and Gill, 1992).

Like its counterpart, $C$. nitida, it has much importance in social life. The tree is respected. Some races plant a seed to commemorate a social event, birth, marriage, etc. Other races consider this impious, and the person doing so will die when that tree flowers. The stock of trees is maintained by the transplanting of naturally 
produced seedlings. The nut has many religions and magical uses. It is commonly an offering to the spirits and genies, and a masticatory during initiations, and a stimulant tonic dances (Burkill, 2000). Yoruba invoke it in an Odu incantation to enable one to wage a successful fight.

Caffeine content of the nuts is $1-2^{1 / 2} \%$. Theobromine is recorded as $0.0023 \%$, tannin $1.618 \%$ with a considerable amount of fructose. Two phenolic substances are recorded, kolatin and kolatein, and other substances. Caffeine is an excitant of the central nervous system, a mental, muscular, respiratory and cardiac stimulant. The nuts are chewed for their stimulant property, though excessive intake can be dangerous. A red pigment, known as "Cola Red" is present in the seed. This is thought to be a part of the tannin content (Burkill, 2000).

Cola nitida on the other hand, is a shrub or tree that grows up to $18 \mathrm{~m}$ tall, usually less, slightly buttressed to $1 \mathrm{~m}$ high with a short bole above to $2 \mathrm{~m}$ girth, bearing a crown of slender ascending branches. It is a shrub of lowland rain- forest, indigenous to Guinea and Ghana but introduced into central Africa. Cultivation has assumed much importance in Nigeria. The bark is used in Liberia in infusion to relieve the pain of fire-burns. In Gabon an infusion of powdered bark is taken to relieve colic, to promote release of bile, and with a little salt and some corns of Xylopia aethiopica (Annonaceae) for coughs. In Ghana the insoluble part from leaf-ash is used in making snuff. The small roots are a common item of market trade in Senegal, sold as toothbrushes (Burkill, 2000). The kernels have place in all social ceremonies, baptisms, marriages, funerals and fetish sacrifices. In Mali, the fruit is a part of prescription, known as saraka issued by soothsayers. Fang of Gabon use pieces of the bark along with egg in acts of magic (Irvine, 1961).

Of the four Cola spp of major interest, C. acuminata, C.anomala, C. nitida and C. verticillata. C. nitida is the most important. The kernels are valued as a masticatory conferring tonic, stimulant, invigorantand excitant symptoms. They produce a capacity for sustained physical effort and for annulling pangs of hunger. Gut secretions and peristaltic movement are increased as is blood pressure. Flavour of the nut is bitter. The principle stimulant is caffeine, 1.5 to $2.5 \%$. The cultivation of this species has shown up varieties, red-seeded and white seeded but with little difference in caffeine content between them. But the white-seeded form seems perhaps on eyeappeal, to be given favour, and is accorded the title of 'The Chief's or King's Kola. Other substances present are theobromine, $0.023 \%$, tannins, $1.618 \%$, fructose, a phenolic substance, kolatin, and a glycoside, kolanin. The caffeine is not free but is bonded to the tannin in a complex but having the same effect as free caffeine. The seed kernels are official in the British Pharmaceutical Codex and the U.S. National Formulary. Besides used as a masticatory, the kernels have use as a flavouring in the burgeoning 'coke' drinks industry. Medicine-men in Ivory Coast prepare the kernels in decoctions, enemas or injections as an aphrodisiac, or in cases of difficult labour as an ecbolic. In Nigeria, it is prescribed as a restorative to stimulate the nervous system and to counteract strain and depression.

According to Adewole et. al. (2013), Kola contains about two percent caffeine and is chewed by many people as a stimulant. It is used in the manufacture of dyes. It is also used in the manufacture of the cola group beveragescoca-cola, Pepsi cola and kola (Javies, 2002). Plants have been used since antiquity for medicinal purposes by diverse peoples and cultures throughout the world. Indeed, the recorded use of natural products as a source of relief from illness dates back at least four thousand years and it can be assumed that unrecorded practices are as old as mankind (Christophersen et. al., 1991). The use of plants for medicinal purposes continues to this day, usually in the form of traditional medicine, which is now recognized by the World Health Organization (WHO, 2005 ) as a building block for primary health care (Akerele, 1988; WHO, 2005). The vibrant healing power of herbs had been recognized since creation and hence botanical medicine is one of the oldest practiced professions by mankind (Van Wyk and Gericke, 2000; Iwu, 1993). Hamburger and Hostettmann (1991) reported that 25\% of prescribed drugs today are of plants origin. Well-known examples of drugs with plant origins includes aspirin, atropine, digoxin, ephedrine, morphine, quinine, reserpine, vincristine and vinblastine, as well as several plant steroidal2sapogenins which serve as semi-synthetic precursors to the steroidal drugs. The study of plants of 
medicinal importance in the first years of the nineteenth century led to the isolation in crystalline form of such complex substances as Strychnine $\left(\mathrm{C}_{21} \mathrm{H}_{22} \mathrm{O}_{2} \mathrm{~N}_{2}\right)$, Quinine $\left(\mathrm{C}_{20} \mathrm{H}_{24} \mathrm{O}_{2} \mathrm{~N}_{2}\right)$ and Morphine $\left(\mathrm{C}_{17} \mathrm{H}_{19} \mathrm{O}_{3} \mathrm{~N}\right)$ which have physiological actions in man and animals (Farnsworth and Bingel, 1997). Herbal medicine has for too long been neglected in favor of synthetic drugs of which its misuse or abuse and cases of side effects have become a social evil (Farnsworth, 1990).

Similarly, according to Durand Dah-Nouvlessounon et. al. (2015), In West African's forest areas, Cola is perhaps second in importance to the palm tree as an indigenous cash crop. Cola nut has been an important article of international trade in many parts of Africa. The nuts of $C$. nitida contain about two percent of caffeine and are chewed by many people as a stimulant. It is a very special and important item used in social and ceremonial activities by Africans. The nuts of cola also have industrial usage for the production of drugs, soft drinks, wines, candies, and beverages such as Coca-Cola and Pepsi-Cola (Jayeola, 2001). It has many pharmacological properties and contains some active principles: it prevents sleep, thirst, and hunger and acts as an antidepressant. The Cola nuts are source of antioxidants and contain a wide array of complex secondary plant metabolites such as theobromine, d-catechin, L-epicatechin, and kolatin (Lowor et. al., 2010). The use of the plant in the treatment of certain diseases has been reported by several authors (Muhammad and Fatima, 2014).

The two species have corresponding economic and cultural values. They are commonly planted around villages. Preferences are shown. C. nitida has a higher caffeine content, and is required for overseas export, but forest people in Nigeria familiar with C. acuminata. prefer it. Seeds of the two species are distinguishable on the basis of the number of cotyledons, C. nitida with 2, C. acuminata 3 to 6.

\section{Statement of the Problem and 0bjective of the Study}

The underutilization of the leaves of Cola acuminata and C. nitida when compared with other parts of the Kola nut tree by humans calls for curiosity. The leaves of the two species are readily available all through the seasons of the year but in spite of this, its level of utility by man is very low. In view of this, scientific information especially in the fields of phytochemistry, pharmacognosy and toxicology about the leaves of these species is therefore imperative.

\section{MATERIALS ANd Methods}

\section{Preparation of Leaf Samples}

The leaf samples were prepared following Otoide and Kayode (2011). The leaves were air-dried and ground into powder using a Thomas Willey milling machine. The aqueous extract of each sample was prepared by soaking $100 \mathrm{~g}$ of dried powdered samples in $200 \mathrm{ml}$ of distilled water for 12 hours. The extracts were filtered using Whatman filter paper (No 42-125mm).

\section{Phytochemical Screening}

Standard procedures of Sofowora (1993), Trease and Evans (1989), Harborne (1973) and Mohammad et. al. (2013) were adopted in the phytochemical screening of the aqueous extract and powdered samples.

\section{Test for Tannins}

Dried powdered samples $(0.5 \mathrm{~g})$ were boiled in $20 \mathrm{ml}$ of water, in a text-tube and then filtered. A few drops of $0.1 \%$ Ferric chloride was added and observed. Brownish-green or blue-black colour indicates the presence of tannins (Trease and Evans, 1989).

\section{Test for Saponins}

Powdered samples $(2 \mathrm{~g})$ were boiled in $20 \mathrm{ml}$ of distilled water in a water bath and filtered. $10 \mathrm{ml}$ of the filtrate was mixed with $5 \mathrm{ml}$ of distilled water and shaken vigorously for a stable persistent froth. The frothing was 
mixed with three drops of olive oil and shaken vigorously and formation of emulsion was observed for the presence of saponin (Sofowora, 1993).

\section{Test for Flavonoids}

Dilute ammonia ( $5 \mathrm{ml}$ ) was added to a portion of the aqueous filtrate of each of plant extract followed by addition of $2 \mathrm{ml}$ concentrated $\mathrm{H}_{2} \mathrm{SO}_{4}$. A yellow coloration observed in each extract indicated the presence of flavonoids (Trease and Evans, 1989).

\section{Test for Alkaloids}

The method of Harbone (1973) was used in this test. The sample (5g) was weighed into a $250 \mathrm{ml}$ beaker and $200 \mathrm{ml}$ of $10 \%$ acetic acid in ethanol was added and covered, and allowed to stand for $4 \mathrm{hrs}$. This was filtered and the extract was concentrated on a water bath to one-quarter of the original volume. Concentrated ammonium hydroxide was added drop wise to the extract until the precipitation was complete. The whole solution was allowed to settle and the precipitate was collected and washed with dilute ammonium hydroxide and then filtered. The residue, which was the alkaloids, was dried and weighed.

\section{Determination of Total Phenol by Folin-Reagent Method}

Total phenol content was determined by Folin-Ciocalteu reagent method with modification. From each crude extracts $(1 \mathrm{mg})$ was dissolved in methanol $(1 \mathrm{~mL})$. A total of $10 \%$ Folin-Ciocalteu reagent was prepared by adding Folin-Ciocalteu reagent $(10 \mathrm{~mL})$ in water $(90 \mathrm{~mL})$. Then, $5 \% \mathrm{Na}_{2} \mathrm{CO}_{3}(3 \mathrm{~g})$ was prepared by dissolving $\mathrm{Na}_{2} \mathrm{CO}_{3}(3 \mathrm{~g})$ in water $(50 \mathrm{~mL})$. Each crude sample $(200 \mu \mathrm{L})$ was taken in a test tube and added $10 \%$ FolinCiocalteu reagent $(1.5 \mathrm{~mL})$. Then all the test tube was kept in a dark place for 5 min. Finally, $5 \% \mathrm{Na}_{2} \mathrm{CO}_{3}(1.5$ $\mathrm{mL}$ ) was added to the solution and mixed well by hand. Again all the test tube was kept in the dark for $2 \mathrm{~h}$. The absorbance was measured for all solution by using UV-spectrophotometer at constant wavelength $750 \mathrm{~nm}$ (Mohammad et. al., 2013)

\section{RESULTS AND DISCUSSION}

The results obtained in the present study revealed the occurrences of Flavonoids, Phenols, Tannins, Alkaloids and Saponins in the leaves of Cola acuminata and Cola nitida. These have been summarized in Tables 1 and 2

Cola acuminata contained $26.71 \pm 12.24 \mathrm{mgQE} / \mathrm{g}, 23.52 \pm 7.84 \mathrm{GAE} / \mathrm{g}, 15.32 \pm 5.11 \mathrm{mgTAE} / \mathrm{g}, 1.23 \pm 0.41 \mathrm{mg} / \mathrm{g}$ and $0.22 \pm 0.07 \mathrm{mg} / \mathrm{g}$ of Flavonoids, Phenols, Tannins, Alkaloids and Saponins respectively. On the other hand, Cola nitida contained $70.03 \pm 23.34,22.96 \pm 7.65,13.44 \pm 4.48,1.01 \pm 0.34$ and $0.16 \pm 0.05$ of Flavonoids, Phenols, Tannins, Alkaloids and Saponins respectively (Table 2).

The leaves of Cola acuminata and Cola nitida are often neglected by humans when anything has to do with these two species. The immediate points of call are their fruits and barks. Conventional knowledge revealed that the leaves of these two species are readily available while their fruits are seasonal yet, the leaves are often neglected.

Available literatures revealed a lot of documented results of complete researches on Cola acuminata and Cola nitida in the fields of science, applied science, social science and marketing on theirs seeds, stem, bark and sometimes fruits. Conversely and surprisingly, the leaves of these two species have not received warmth attention of researchers just like the leaves of other plant taxa even in ethnomedicine. This has led to dearth of scientific reports regarding this special organ of these species. Whereas, the most common plant organ where medicinal properties are domiciled is the leaf.

Results obtained in the present study showed that the leaves of these two species of Cola, though often neglected in day to day activities by humans are not devoid of phytochemicals and other useful constituents. The occurrences of Flavonoids, Phenols, Tannins, Alkaloids, Saponnins in the leaves of both species are proofs 
of therapeutic values inherent in them. This claim is warranted by the assertions of Hill (1952 and Rabiu et. al., 2018) that the medicinal value of plants lies in some chemical substances that produce a definite physiological action on the human body. The most important of these bioactive constituents of plants are alkaloids, tannins, flavonoids and phenolic compounds. The reports of Chong et. al. (2012), Diaz et. al; (2015) and Adoum (2016) that biologically active compounds like alkaloids, phenolic compounds, saponins, flavonoids and many others with known antioxidant and antibacterial properties, can be of great significance in therapeutic treatment also support the authors claim made above.

It is known that different phytochemicals have a broad range of pharmacological activities. For instance, saponins can be used as an anti-inflammatory agent and in treatment for tuberculosis; steroids were used as allergy, arthritis and coronary failure therapy, control in menstrual cycle and increasing women fertility; alkaloids can increase nutrient absorption and blood circulation, reduce pain and stimulate nerve system as it has narcotic effect; and tannins are reported to possess anti-irritant, anti-secretolytic, anti-phlogistic, antimicrobial and anti-parasitic effects (Ong et. al., 2004). Moreover, flavonoids are well documented to have important effects on various biological systems. Flavonoids have been referred as "nature's biological response modifiers" because of strong experimental evidence of their inherent ability to modify the body's reaction to allergens, viruses, and carcinogens. They show anti-allergic, anti-inflammatory, antimicrobial and anticancer activities (Cushnie and Lamb, 2005; YIN et. al; 2013).

Table1. Qualitative Composition of the Phytochemicals in the Leaves of the Cola Species

\begin{tabular}{|c|c|c|c|c|c|}
\hline \multicolumn{2}{|c|}{ Species } & \multicolumn{4}{c|}{ Phytochemicals } \\
\hline & Alkaloids(mg/g) & Tannins(mgTAE/g) & Saponin(mg/g) & Flavonoids(mgQE/g) & Phenols(mgGAE/g) \\
\hline Cola acuminata & + & + & + & + & + \\
\hline Cola nitida & + & + & + & + & + \\
\hline
\end{tabular}

Table2. Quantitative Compositions of the Phytochemicals in the Leaves of the Cola Species

\begin{tabular}{|c|c|c|c|c|c|}
\hline \multicolumn{2}{|c|}{ Species } & \multicolumn{4}{c|}{ Phytochemicals } \\
\hline & Alkaloids(mg/g) & Tannins(mgTAE/g) & Saponin(mg/g) & Flavonoids(mgQE/g) & Phenols(mgGAE/g) \\
\hline Cola acuminate & $1.23 \pm 0.41$ & $15.32 \pm 5.11$ & $0.22 \pm 0.07$ & $26.71 \pm 12.24$ & $23.52 \pm 7.84$ \\
\hline Cola nitida & $1.01 \pm 0.34$ & $13.44 \pm 4.48$ & $0.16 \pm 0.05$ & $70.03 \pm 23.34$ & $22.96 \pm 7.65$ \\
\hline
\end{tabular}

It is pertinent to report here that the leaves of the two Cola spp in the present study are not been browsed by herbivores. This phenomenon could be attributed to the occurrence of great quantity of tannins in them. This notion is possible since Woodward and Cappock (1995) opined that the presence of tannins, spines and other physical attributes are capable of reducing browse palatability of plants. This might be ecologically advantageous to these species as they will be able to compete for the available resources in their environment.

In conclusion, the negligence of the leaves of these species of Cola has contributed greatly to their under-utility in many specific ways. To this end, the authors wished to call for further researches in the fields of Biochemistry, Pharmacology, Pharmacognosy and Pharmacy in order to confirm the novel bioactive compounds derivable from them and which can be precursors for synthesis of useful drugs.

\section{REFERENCES}

1. Adoum O. A. (2016). Screening of Medicinal Plants Native of Kano and Jigawa States of Northern Nigeria Using Artemia cysts (Brine Shrimp Test). American Journal of Pharmaceutical Sciences, 4 (1):7-10.

2. Akerele, O. (1988). Medicinal plants and primary health care: An agenda for action. Fitoterapia. 59: $355-363$ 
Phytochemical Study of Underutilized Leaves of Cola acuminata and C. nitida

3. Burkhill, H. M. (2000). The useful plants of West Tropical Africa. Vol.2, $2^{\text {nd }}$ Edn; Royal Botanic Gardens, Kew, pp. 654-670

4. Chong, K. P, Atong, M, and Rossall, S. (2012): The roles of syringic, caffeic and 4- hydroxybenzoic acids in Ganoderma - oil palm interaction. Asian J. Microbiology, Biotechnol and Environmental Sci. 14(2):157-166.

5. Christophersen, C., Larsen C. and Dimayuga, R. E. (1991). Traditional Medicine-A Potential Resource Exploitation of Natural Products. The H.C. Orsted Institute, Copenhagen, Denmark. 8-12.

6. Cushnie, T. P. T. and Lamb, A. J. (2005): Antimicrobial activity of Flavonoids. Int. J. Antimicrob. Agents. 26 (5): 343-356

7. Dewole, E. A., Dewumi, D. F. A., Alabi, J. Y. T. and Adegoke, A. (2013): Proximate and Phytochemical of Cola nitida and Cola acuminata. Pakistan Journal of Biological Sciences. 16(22): 1593-1596

8. Diaz G., Miranda I. L. and Diaz M. A. N (2015): Quinolines, Isoquinolines, Angustureine and Congeneric Alkaloids- Occurrence, Chemistry and Biological Activity. Intechopen publishers.

9. Durand, D. N., Hubert, A. S., Nafan, D., Haziz, S., Adolphe, A., Mariam, I., Donald, A., Joachim D. G., Simeon, O. K., Mamoudou, H. D. and Lamine, B. M. (2015): Phytochemical Analysis and Biological Activities of Cola nitida Bark. Biochemistry Research International. 1-9

10. Farnsworth, N. R., (1990). The Role of Ethno-pharmacology in Drug Development. In: Bioactive Compounds from Plants (Ciba foundation Symposium 154), Chadwick D. J. and J. Marsh (Eds.). Wiley, Chichester. U.K: $2-21$.

11. Farnsworth, N. R. and Bingel, A. S. (1997). Problems and Prospects of Discovering New Drugs from Higher Plants by Pharmacological Screening. In: New Natural Products and Plants Drugs with Pharmacological, Biological or Therapeutic Activity, Wagner, H. and P. Wolff (Eds.).Springer. Berlin. 1-22.

12. Gill, L.S. (1992): Ethno medicinal uses of plants in Nigeria. University of Benin Press. 350P

13. Harbone, J. B., (1973). Phytochemical Methods: A Guide to Modern Techniques of Plant Analysis. Chapman and Hall, London. 267-270.

14. Harmburger, M. and Hostettmann, K. (1991). Bioactivity in plants: The link between phytochemistry and medicine. Phytochemistry. 30: 3864-3784.

15. Hill, A. F. (1952). Economic Botany: A textbook of useful plants and plants products. $2^{\text {nd }}$ edn. Mc Garw- Hill Book Company Inc., New York, USA

16. Irvine, F. R. (1961). Woody Plants of Ghana with special reference to their uses. Oxford University Press, Amen House, London. 868Pp.

17. Iwu, M. M. (1993). Handbook of African Medicinal Plants. CRC Press Boca Raton, FL, USA :26-267

18. Jayeola, C. O. (2001) "Preliminary studies on the use of kolanuts (Cola nitida) for soft drink production, "Journal of Food Technology in Africa. 6 (1): 25-26

19. Javies, G., (2002). The rise and fall of cocaine cola. http://www.unz.org/Pub/LewRockwell-2002may00039 .

20. Leyinson, H. Z. (1976): The defensive role of alkaloids in insects and plants. Cellular and Molecular life Sci. 32: 408-411.

21. Lowor, S. T., Aculey, P. C and Assuah, M. K. (2010):"Analysis of some quality indicators in cured Cola nitida (Vent)". Agriculture and Biology Journal of North America, 1(6): 1206-1214.

American Research Journal of Biosciences

Page 6 
22. Mohammad, A. H., Khulood, A. S. AL- Raqmi, Zawan, H. AL- Mijizy, Afaf, M. W. and Qasim AL- Riyami. (2013): Study of total phenol, flavonoids contents and phytochemical screening of various leaves crude extracts of locally grown Thymus vulgaris. Asian Pac. J. Trop. Biomed. 3(9): 705-710

23. Muhammad, S. and Fatima, A. (2014): "Studies on phytochemical evaluation and antibacterial properties of two varieties of kolanut (Cola nitida) in Nigeria" Journal of Biosciences and Medicines. 2(3):37-42.

24. Ong, H. C. (2004): Tumbuhan liar. Khasiat ubatan dan kegunaan lain. Kuala Lumpur: Utusan Publication and Distributor. 6-9.

25. Otoide, J. E. and Kayode, J. (2011) phytochemical study of some plants commonly used as herbal remedies in Southern Nigeria. Bulletin of pure and Applied Sciences. Vol. 30B-Botany. 20(1-2): 33-40.

26. Rabiu, M. K, Safiya, A, Sani, A. K and Gambo, C. (2018): Phytochemical Compositions in Some Nigerian Medicinal Plants and Their Pharmacological Properties: A Review. Journal of Anesthesiology. 6(1):15-25.

27. Rout, S. P., Choudary, K. A., Kar, D. M., Das, L. and Jain, A. (2009): Plants in traditional medicinal system future source of new drugs. Int. J. Pharm. Pharmaceutical Sci.1: 1-23.

28. Sofowora, A. (1993): Medicinal Plants and Traditional Medicine in Africa. (2 ${ }^{\text {nd }}$ edition) Spectrum Books Limited, Sunshine House, Ibadan, Nigeria.

29. Trease, G. E. and Evans, W. C. (1989). Pharmacognosy.11 $1^{\text {th }}$ Edn. Brailliar Tiridel Can. Macmillian Publishers.

30. Van Wyk, B. E. and Gericke, N. (2000): People's Plants: A Guide to Useful Plants of Southern Africa. Briza Publications, Pretoria, South Africa. 351Pp.

31. Woodward A. and Coppock, D. L. (1995): Role of plant defense in the utilization of native browse n Southern Ethiopia. Agrofor. Syst. 32:147-161

32. World Health Organization. (2005): World malaria report. World Health Organization, Geneva, Switzerland.

33. Yin, N. S, Abdullah, S and Phin, C. K. (2013): Phytochemical constituents from leaves of Elaeis guineensis and their antioxidant and antimicrobial activities. Int. J. Pharm. and Pharmaceutical Sc. 5(4): 137-140

Citation: Otoide Jonathan Eromosele, Olanipekun Mary Kehinde "Phytochemical Study of Underutilized Leaves of Cola acuminata and C. nitida". American Research Journal of Biosciences; V4, I1; pp: 1-7.

Copyright (c) 2018 Otoide Jonathan Eromosele, Olanipekun Mary Kehinde, This is an open access article distributed under the Creative Commons Attribution License, which permits unrestricted use, distribution, and reproduction in any medium, provided the original work is properly cited. 